\title{
Care Providers' Perspectives on Disrespect and Abuse of Women During Facility-Based Childbirth in Ethiopia: A Qualitative Study
}

\author{
Yohannes Mehretie Adinew ${ }^{1,2}$ \\ Janet Kelly ${ }^{\prime}, *$ \\ Amy Marshall ${ }^{3 * *}$ \\ Morgan Smith ${ }^{1} *$ \\ 'Adelaide Nursing School, The University \\ of Adelaide, Adelaide, Australia; ${ }^{2}$ College \\ of Health Sciences and Medicine, Wolaita \\ Sodo University, Sodo, Ethiopia; ${ }^{3}$ College \\ of Nursing and Health Sciences, Flinders \\ University, Adelaide, Australia \\ *These authors contributed equally to \\ this work
}

Background: It is increasingly evident that disrespect and abuse of women during facility-based childbirth is a violation of a woman's rights and a deterrent to the use of life-saving maternity care. Understanding care providers' perspectives of disrespect and abuse during facility-based childbirth is an essential element to aid in fully comprehending the problem and its underlying complexities. Objective: To explore care providers' perspectives of disrespect and abuse during facilitybased childbirth.

Methods: This study used a qualitative descriptive design involving fifteen in-depth, semistructured, interviews conducted between 5 October 2019 and 25 January 2020 in north Showa zone of Oromia region, central Ethiopia. Purposive sampling enabled health care professionals working in maternity units of health facilities who have direct involvement in care of women during pregnancy and labor to be recruited. Thematic analysis using Open Code software was used to explore the perspectives of participants.

Results: Four themes were identified. 1) Disrespect and abuse breaches professional standards, 2) Disrespectful and abusive actions are justified at times to save the mother and her baby, 3) Disrespect and abuse is used as a tool to assert power, and 4) Disrespect and abuse arise from health system deficiencies.

Conclusion: Disrespect and abuse is triggered by underlying beliefs about risk versus care, provider attitudes, stress and burnout, and health service structural issues including a lack of medicines and supplies. A number of strategies could improve the quality of maternity care, including training providers how to manage difficult and complex situations, addressing root causes of disrespect and abuse, and increasing access to resources.

Keywords: health care workers, disrespect, human rights abuses, respect, birthing centers, Ethiopia

\section{Background}

Almost half of the pregnancy-related deaths in the world are from Sub-Saharan Africa. ${ }^{1}$ Most of these deaths occur during the intrapartum period, highlighting the need to focus on this period of care. It is estimated that approximately four million African women and babies would survive annually if $90 \%$ of families receive known interventions. ${ }^{2}$ The most effective and cost-efficient strategy for reducing maternal and neonatal mortality in low resource countries is encouraging women to give birth in a health facility with the assistance of a skilled birth attendant. ${ }^{3}$

However, women in developing countries have limited access to obstetric care for several reasons including, but not limited to: gender discrimination, traditional beliefs, financial constraint and lack of accessible and reliable transportation. ${ }^{4,5}$ Previous research
Correspondence: Yohannes Mehretie Adinew

Tel $+25191-202-1605$

Email yohannes.adinew@adelaide.edu.au 
has suggested that the treatment women receive in birthing facilities may be substandard and serve as a deterrent to them attending facility-based childbirth. ${ }^{6}$ Poorer quality of care, ${ }^{7,8}$ and poor health worker attitudes contribute to a woman choosing to use a traditional provider. ${ }^{9,10}$ Studies from southern Ethiopia have concluded that women who chose not to give birth in a health facility cited negative provider attitudes, ${ }^{11}$ poor quality maternity services and limited availability of trained staff $^{12}$ as the primary reasons. According to the 2019 Ethiopian demographic and health survey, ${ }^{13} 50 \%$ of births are not supervised by a skilled birth attendant and $48 \%$ of deliveries occur outside a health care facility in Ethiopia. Consequently, improving maternal and child health remains a challenge for a nation where 401 women died per 100,000 live births in $2017,{ }^{14}$ and 1 in every 30 children die within the first month. ${ }^{13}$

Disrespect and abuse (D\&A) of women during facilitybased childbirth is a violation of human rights and an indicator of poor quality of care, ${ }^{15}$ and has been identified as a key deterrent to facility based childbirth in developing nations. ${ }^{16}$ The provider-client relationship and experience of care is of central importance, it impacts on access, compliance, quality, and effectiveness, ${ }^{17-19}$ as well as the care seeking practices of women. ${ }^{20}$ There is growing realization that any approach to care that ignores the importance of this relationship and the culture of care provision, is fundamentally flawed. This has led to a recent global move towards a more person-centered approach. $^{21}$

Healthcare providers play a central role in improving the quality of maternity care and reducing maternal deaths. Therefore, any research and strategy to address disrespectful and abusive treatment must include the perspectives and experiences of healthcare providers themselves. Previous studies conducted in Ethiopia have primarily focused on reports from women, while few sought insights from practicing providers. $^{22}$ A better understanding of both perspectives is essential to accurately understand the problem and underlying complexities and identify the drivers of change to inform improvement interventions. Therefore, this paper aims to explore how providers perceive various actions that could be classified as mistreatment by an independent observer, researcher, or advocate.

\section{Methods}

\section{Study Design}

Interviews with health professionals were conducted as part of a larger mixed methods study ${ }^{23}$ that examined disrespect and abuse of women during facility-based childbirth in Ethiopia from the perspectives of women and health care providers. A qualitative descriptive design was used to understand the perspectives of care providers, ${ }^{24}$ and the phenomenon under investigation. ${ }^{25}$

\section{Study Setting}

This study was conducted in north Showa zone of Oromia region, central Ethiopia, located $110 \mathrm{~km}$ to north of the capital Addis Ababa. The total population is approximately 1.5 million and $48 \%$ are women. ${ }^{26}$ Afan Oromo and Amharic are the main languages spoken. There are three hospitals, 62 health centers and 268 health posts in this zone. Study facilities were chosen based on their number of staff and client volume.

\section{Participants}

Midwives, nurses, general practitioners, and obstetricians working at maternity units of selected health facilities with direct involvement in the care of women during pregnancy and labor were enrolled in this study. Healthcare providers who do not work at the maternity ward of the study facilities were ineligible to participate. Participants worked in two hospitals and three health centers with urban and rural areas included. Health posts were not included as they do not provide birthing care.

\section{Recruitment of Study Participants}

A project information flyer was posted in maternity units and the project eligibility criteria was presented to staff, following permission from administrators. Interested care providers contacted the investigator, provided informed consent, and participated in semi structured interviews. Purposive sampling was used to enroll participants across a range of health professions and experiences. Information saturation (when ideas started to be repeated and no more new ideas emerged) was used to determine the final number of in-depth interviews (IDIs).

\section{Data Collection Tool and Procedures}

The research team used previous systematic review findings to develop a semi-structured interview guide that addressed differing forms of disrespect and abuse that women may experience during childbirth. ${ }^{27,28}$ Nine examples were developed and used during the interviews to elicit responses from participants about whether, when, and in what circumstances abuse and neglect occurs and whether each scenario was viewed by the participant as acceptable or unacceptable (Table 1). Fifteen IDIs were conducted from 5 October 2019 
Table I Sample Disrespect and Abuse Questions

\begin{tabular}{|c|c|}
\hline No. & Questions \\
\hline $\mathrm{I}$. & $\begin{array}{l}\text { If a woman was pinched or slapped by a health worker during } \\
\text { her childbirth, would this be acceptable? When would it be } \\
\text { acceptable? } \\
\text { If a woman was yelled or shouted at by a health worker during } \\
\text { her childbirth, would this be acceptable? When would it be } \\
\text { acceptable? }\end{array}$ \\
\hline 3. & $\begin{array}{l}\text { If a health worker was mean and refused to help a woman } \\
\text { during her delivery, would this be acceptable? When would it } \\
\text { be acceptable? }\end{array}$ \\
\hline 4. & $\begin{array}{l}\text { If a health worker physically held a woman down during her } \\
\text { childbirth, would this be acceptable? When would it be } \\
\text { acceptable? }\end{array}$ \\
\hline 5. & $\begin{array}{l}\text { If a health worker threatens a woman by unfavorable } \\
\text { procedure like CS or referral or bad outcome for her or her } \\
\text { baby during her childbirth, would this be acceptable? } \\
\text { When would it be acceptable? }\end{array}$ \\
\hline 6. & $\begin{array}{l}\text { If a health worker disallowed a woman to deliver in a position } \\
\text { of her choice during her childbirth, would this be acceptable? } \\
\text { When would it be acceptable? }\end{array}$ \\
\hline 7. & $\begin{array}{l}\text { If a health worker performs a procedure without getting } \\
\text { consent during her childbirth, would this be acceptable? When } \\
\text { would it be acceptable? }\end{array}$ \\
\hline 8. & $\begin{array}{l}\text { If a health worker forcefully opens a woman's leg during her } \\
\text { childbirth, would this be acceptable? When would it be } \\
\text { acceptable? }\end{array}$ \\
\hline 9. & $\begin{array}{l}\text { If a health worker disallowed a woman birth companion during } \\
\text { her childbirth, would this be acceptable? When would it be } \\
\text { acceptable? }\end{array}$ \\
\hline
\end{tabular}

to 25 January 2020. Participants were interviewed in private rooms in health facilities during working hours. Interviews lasted approximately 50 minutes. Care was taken to maintain confidentiality of study participants by de-identifying interview transcripts and maintaining privacy during interviews. Healthcare providers were invited to reflect on the occurrence and "acceptability" of hypothetical mistreatment during childbirth, rather than disclosing personal instances of mistreatment. The interviews were audio (voice) recorded with permission, with field memos also taken.

\section{Data Analysis}

A thematic analysis approach as described by Braun and Clarke (2006) was used to identify key themes, richly describe large bodies of qualitative data and highlight similarities and differences in experiences. ${ }^{29}$ IDIs were conducted in a local language (Afan Oromo or Amharic) by the primary author, translated and transcribed simultaneously by the primary author and reviewed by another experienced bilingual researcher in Ethiopia. De-identified transcripts were stored on a password protected computer. Open coding was performed line-by-line on the transcripts by the primary author and the co-authors to develop an initial thematic framework. Codes were then analyzed alongside field memos to generate categories. Themes were identified and representative quotes were selected to illustrate the range of voices in each theme.

Reliability testing was conducted in two stages: (1) two researchers jointly coded five transcripts and (2) then independently coded four transcripts and discussed coding decisions until consensus. A subset of the coded transcripts was reviewed by an independent researcher to check reliability of the coding. Open Code software version 4.0.2.3 was used for the data analysis. This paper is reported according to the consolidated criteria for reporting qualitative research (COREQ). ${ }^{30}$

\section{Results}

A total of 15 IDIs were conducted and included in this analysis: 11 midwives/nurses, three general practitioners and one obstetrician participated. Table 2 reports sociodemographic characteristics of participants (Table 2).

\section{Views of Acceptability of Disrespect and Abuse During Childbirth}

A range of viewpoints emerged from the interviews with care providers. These were arranged in four main themes, each with a number of subthemes. (1) Disrespect and abuse breaches professional standards, (2) Disrespectful and abusive actions are justified at times to save the mother and her baby, (3) Disrespect and abuse is used as a tool to assert power, and (4) Disrespect and abuse arise from health system deficiencies (Figure 1).

\section{Disrespect and Abuse Breaches Professional Standards}

Disrespectful and abusive treatment during childbirth in facilities not only violates the rights of women to respectful care, but can also threaten their rights to life, health, and bodily integrity. Participants were very clear that D\&A is not acceptable under any circumstance because of three reasons. First, according to participants, D\&A 
Table 2 Socio Demographic Characteristics of Study Participants

\begin{tabular}{|c|c|c|c|c|}
\hline & & $\begin{array}{c}\text { Obstetrician } \\
n=1\end{array}$ & $\begin{array}{c}\text { General } \\
\text { Practitioners } \\
\mathbf{n}=3\end{array}$ & $\begin{array}{c}\text { Midwives/ } \\
\text { Nurse } \\
n=I I\end{array}$ \\
\hline $\begin{array}{l}\text { Age } \\
\text { (years) }\end{array}$ & $\begin{array}{l}<30 \\
30-39 \\
40-49 \\
50+\end{array}$ & $\begin{array}{l}0 \\
0 \\
1 \\
0\end{array}$ & $\begin{array}{l}0 \\
2 \\
1 \\
0\end{array}$ & $\begin{array}{l}3 \\
6 \\
2 \\
0\end{array}$ \\
\hline $\begin{array}{l}\text { Marital } \\
\text { status }\end{array}$ & $\begin{array}{l}\text { Married } \\
\text { Single }\end{array}$ & $\begin{array}{l}1 \\
0\end{array}$ & $\begin{array}{l}3 \\
0\end{array}$ & $\begin{array}{c}11 \\
0\end{array}$ \\
\hline Gender & $\begin{array}{l}\text { Female } \\
\text { Male }\end{array}$ & $\begin{array}{l}0 \\
1\end{array}$ & $\begin{array}{l}0 \\
3\end{array}$ & $\begin{array}{l}5 \\
6\end{array}$ \\
\hline $\begin{array}{l}\text { Years of } \\
\text { experience }\end{array}$ & $\begin{array}{l}0-4 \\
5-9 \\
10-14 \\
15+\end{array}$ & $\begin{array}{l}1 \\
0 \\
0 \\
0\end{array}$ & $\begin{array}{l}1 \\
2 \\
0 \\
0\end{array}$ & $\begin{array}{l}4 \\
4 \\
3 \\
0\end{array}$ \\
\hline $\begin{array}{l}\text { Facility } \\
\text { type }\end{array}$ & $\begin{array}{l}\text { Health } \\
\text { centre } \\
\text { Hospital }\end{array}$ & $\begin{array}{l}0 \\
1\end{array}$ & $\begin{array}{l}0 \\
3\end{array}$ & $\begin{array}{l}7 \\
4\end{array}$ \\
\hline $\begin{array}{l}\text { Facility } \\
\text { location }\end{array}$ & $\begin{array}{l}\text { Rural } \\
\text { Semiurban } \\
\text { Urban }\end{array}$ & $\begin{array}{l}0 \\
0 \\
1\end{array}$ & $\begin{array}{l}1 \\
1 \\
1\end{array}$ & $\begin{array}{l}5 \\
4 \\
2\end{array}$ \\
\hline
\end{tabular}

demonstrates a lack of understanding of the feelings of others when care providers fail to empathize with the woman and her circumstance. Secondly, participants denounced D\&A based on ethical principles. According to these participants, D\&A breaches professional standards of clinical care. Thirdly, participants suggested D\&A contributes to an undesirable delivery outcome by affecting the communication between the provider and the woman. These participants prioritized respectful care as part of professional practice and believed that understanding the woman and treating her with respect contributes to good rapport and a positive birth outcome.

\section{Disrespect and Abuse Fails to Acknowledge Women's Circumstances}

Women have a right to expect empathy from their healthcare provider. Only three of the participants, all of whom were doctors, considered the majority of the presented D\&A scenarios as unacceptable One participant stressed that providers should approach and treat all laboring women with consideration and empathy.

I feel providers have to understand the woman if she does not comply with their instructions. Because she is in an immense pain and they do not know what she does. She may not respond to your question or disappoint you with inappropriate response. However, the provider has to be patient. (male doctor, urban hospital)

Care providers will gain a woman's cooperation if they approach her with respect and patiently explain procedures to her. A participant had also similar viewpoints where he explained how providers should approach and treat women:

Disrespect and abuse breaches
professional standards

\section{Disrespectful and abusive actions are justified at times to save the mother and her baby}

Disrespect and abuse is used as a tool
to assert power
$\begin{aligned} & \text { Disrespect and abuse arise from health } \\ & \text { system deficiencies }\end{aligned}$

Disrespect and abuse may be necessary for the safety of the mother and her baby

Disrespect and abuse may be necessary to avoid the personal professional consequences of an adverse outcome

Disrespect and abuse arises from feelings of inferiority and professional inadequacy

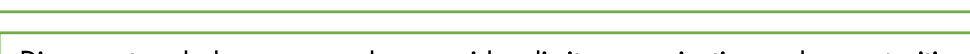

Disrespect and abuse occurs when providers limit communication and opportunities for mutual decision making

Disrespect and abuse arises from an unsupportive management and professional hierarchy

Disrespect and abuse exists when dissonance between knowledge and practice exists

Disrespect and abuse occurs when human and material infrastructure is limited

Figure I Schematic presentation of the identified themes and subthemes. 
She will cooperate if you explain the importance of the procedure to her baby. However, this depends on our patience and approach. Thus, providers should avoid bossy approach because women will feel looked down on them. It is too much to expect the woman to tolerate bad approach of providers on top of the labor pain. (male doctor, urban hospital)

Labor pain or a lack of knowledge of the physiology of childbirth might influence the woman's interaction with care providers. According to participants, providers have to recognize this and treat women accordingly. These participants believe that any "wrongdoing" of the women could be due to lack of awareness or because of their circumstances and care providers have to understand them. A participant said,

Who can understand her situation without care providers? Shouting does not help either, you have to be respectful in your approach. Still if the woman does not cooperate, you better inform her families to intervene rather than getting into conflict with her. (male doctor, urban hospital)

\section{Disrespect and Abuse Breach Professional Standards of Legal and Ethical Conduct}

There were participants who considered the presented D\&A examples unacceptable from legal and ethical point of view. These participants evaluate their actions in relation to the legal consequence they might have. As a result, the majority of participants do not consider pinching or slapping of a mother acceptable. Male providers in particular found it unacceptable to beat a laboring woman. According to these providers, shouting at or beating a woman for any reason is unethical and has legal consequences.

Why on earth you raise your hand on a woman? It is immoral and unethical to beat any woman let alone a laboring mother who came to seek your help. It can never be acceptable. (male midwife, urban hospital) Another midwife had similar views

you cannot slap a woman; it is violation of her rights and you will be held accountable. (male midwife, urban hospital)

Most of the respondents strictly practice the traditional lithotomy position and have never assisted a mother in other preferred birthing positions. However, they considered tying a laboring woman to the delivery bed with ropes to control her from leaving the delivery bed inappropriate and illegal. A participant said,

She is a human being, not animal and never should be tied to the bed. (male midwife, rural health center)

Another midwife said,

it is a crime to tie a laboring woman to a bed, she is not a threat to anyone's safety. (female midwife, rural health center)

Almost all participants considered performing a procedure without getting consent acceptable for various reasons. However, the only obstetrician in the study said:

It is not acceptable to perform any procedure without getting a consent. You have to tell her what you are going to do to the level she can comprehend. It is not acceptable to perform a procedure without her knowledge. If she refuses a medically indicated procedure you can involve her family. If she still insists you will make her sign and leave the hospital at her own risk. It is mandatory to take a consent. (Obstetrician, urban hospital)

Participants were asked if it is acceptable for a health worker to refuse to help a woman during her delivery. All participants of the study, except one midwife, did not consider withholding of care acceptable under any circumstance. They preferred transferring the woman to another provider than abandoning her. A participant said:

Why you withhold the care that she came for? If you cannot continue assisting her because of disagreement, transfer her to another provider. You cannot simply abandon a laboring mother; it is unethical. (male midwife, rural health center)

Another participant stated:

It is unethical. How would you sleep at night peacefully after abandoning a laboring mother? If you cannot attend her for any reason, you must make sure that another provider oversees her. (female midwife, rural health center)

\section{Disrespect and Abuse Can Lead to Adverse Healthcare Outcomes}

Some providers believed that disrespecting or abusing a mother will affect the communication between the provider and the woman and will contribute to an undesirable delivery outcome. According to these participants, if not treated well, the woman may not comply, refuse to undergo procedures, and puts her life in danger. 
Shouting at woman is not acceptable as it damages the relationship and will contribute to bad outcome. (male midwife, rural health center)

Other participant had similar viewpoints,

if you beat her, she will be angry and uncooperative. (Male midwife, urban health center)

Participants considered disrespect and abuse as unacceptable They believed that D\&A breaches professional standards as it fails expectations around legal and ethical conduct, and fails to acknowledge women's circumstance and can lead to adverse outcome.

\section{Disrespectful and Abusive Actions are Justified at Times to Save the Mother and Her Baby}

Some participants considered the D\&A examples acceptable as they prioritize the medically indicated procedures over patient-centered care. For these participants birthing a live baby to a healthy mother is a top priority. Thus, they are willing to do whatever it takes not to risk the lives of either the baby or the mother.

\section{Disrespect and Abuse May Be Necessary for the Safety of the Mother and Her Baby}

Care providers focus on delivering a live baby to a healthy mother and are willing to do whatever it takes. As a result, they considered the disrespect and abuse examples acceptable if the act prevents loss of the mother and her baby.

My primary aim is to deliver a live baby to a healthy mother. She may be uncomfortable with my approach but, I guarantee her a live baby and that is what matters most for me. I will perform procedure without waiting for her approval as long as it is medically indicated. (Female midwife, urban hospital)

This may be the reason why all participants found it acceptable to threaten a woman with a bad outcome or unfavorable procedure or denial of care, forcefully opening her leg and forcefully holding her down to the delivery bed. They believed that these acts cause no harm to the mother, but rather they make her cooperate and give birth without a problem. According to the participants, any psychological or emotional pain of the mother due to these acts are less emotionally painful than losing a baby.
Mother should not lose her baby. So, it is ok to frighten her if it contributes to safe delivery. I believe that the major thing here is to get a live baby to a healthy mother, other issues including respect come next. Do you think the mother will be happy because you were respectful even if she loses her baby? No way. So, first thing first. Give priority to delivering a live baby to a healthy mother. Because undesirable outcome either for the mother or the baby is too costly for the family. (female midwife, rural health center)

Threatening a woman with a bad outcome for her or her baby is considered acceptable. According to some participants, it does not cause any physical harm to the woman.

A female midwife's view supported this argument:

Threatening a woman with poor outcome for her or her baby has no harm and will make her cooperative. If you do not have her cooperation, you may lose the baby or even the mother and that will be an absolute failure. (female midwife, rural health center)

The intention determines the acceptability of an action, according to participants. These participants recognized that the actions are not respectful. However, they are ok with them if the intention is to save the life the mother and her baby.

Shouting at a woman is somehow a common practice in our ward. It is acceptable if it for her own benefit, like to make her concentrate and push. Otherwise, it is against her right to shout at her for reasons not related to her. (female midwife, rural health center)

Another participant had similar views,

No one is here to hurt or disrespect a woman intentionally. We do everything for the sake of the mother and her baby. After all we do not know these women personally and our acts shouldn't be taken personal as well. (doctor, urban hospital)

Almost all participants believed that women should not be allowed to leave the bed during the second stage of labor. As a result, they considered forcefully holding her down to the delivery bed acceptable as an act to save her baby.

The intention is to save her baby, not to limit her right to move around. Because she may suffocate her baby if she sits on it or may lose it to the ground while standing. She may also experience severe genital tear if the baby comes out forcefully. (female midwife, urban hospital)

Another participant justified the act by saying 
You can even do it with help of others. You do this for her own sake, she will kill her baby otherwise. She has waited for nine months to kiss her baby and you should not sit and watch her kill it. (Male midwife, rural health center)

Similarly, even if they know they have to get consent, participants considered doing medically indicated procedures without the women's consent as acceptable to save a life.

Ethically it is inappropriate to touch a woman without her consent let alone performing a procedure. However, if a woman presents with a second stage of labor you do not have time to explain everything to her, you have to act instantly or else you will lose the baby. (male midwife, urban hospital)

According to participants, saving the woman's life is more important than seeking her consent.

What will a woman lose if she undergoes a medically indicated procedure without her knowledge? After all she came to us to give birth and we have to make it happen by any means. You may be wasting precious life saving time. (female midwife, rural health center)

Six participants have considered slapping a woman acceptable as a means to encourage her keep pushing.

If her baby is in distress and she is not pushing enough, you can slap her thigh just to encourage her, or else she will lose her baby in front of your eyes. You do not slap to hurt her, except helping her out. (male midwife, urban hospital)

Similarly, there was a participant who believed that slapping a woman on her thigh is different from slapping her in the face. Thus, it is acceptable to slap women on thigh in order to encourage her or get compliance.

Slapping on the thigh is not disrespectful like the slap in the face, we do this just to make her focused and get compliance. (female midwife, urban hospital)

\section{Disrespect and Abuse May Be Necessary to Avoid Personal Professional Consequences of an Adverse Outcome}

Respondents described a common problem where women in the second stage of labor refuse to push putting themselves and their babies at a higher risk. Participants believed that it is their duty to help women avoid a bad outcome, not only in the best interest of the mother and baby, but also because bad outcomes reflect poorly on them as healthcare professionals. As a result, providers considered the D\&A examples acceptable to avoid legal consequences of undesirable delivery outcome.

If you fail you will be held accountable. So, you have to make sure the woman gets her baby alive at any cost. She will forget all the disrespect and abuse you are talking about after she gave birth. However, is she lose her baby while I am comforting her, rather than urging her to push, I will be blamed. (female midwife, urban hospital)

This may help to explain why some respondents considered their profession as risky.

Maternal death is politicized, and you will be held accountable if something went wrong in your hand. (female midwife, urban hospital)

One provider considered slapping or pinching a woman acceptable to avoid professional consequences of adverse outcomes.

I pinch or slap her to deliver a live baby because I will be responsible if she develops complication or lose her baby. (female midwife, urban hospital)

Some providers considered yelling or shouting at the women acceptable to save their career. They thought shouting at a woman cannot cause any harm to the woman, but rather it reminds her of the seriousness of the situation and will make her cooperate and help them escape consequences of undesirable delivery outcome.

If you do not yell or shout at her, she will ignore your instructions and put you in trouble. If something wrong happens to the mother or her newborn while you are in charge, you will be scrutinized. So, you shout at her to make her onboard [focus and push] and avoid undesirable outcomes. (female midwife, urban hospital)

Forcefully holding down a woman to the delivery bed is considered acceptable by the majority of the participants. These providers feared responsibility of an undesirable delivery outcome and thus they believed that a mother should not be allowed to move out of the delivery bed during the active phase of labor.

You have to hold her to the bed by any means. She will accuse and put you in big trouble if she loses her baby and nobody will be there in your defense. You have to make sure things end well or else the consequence is not good 
for your career as a midwife. (female midwife, urban hospital)

There were also participants who considered performing a procedure without consent as acceptable to protect their professional career. These participants argued that obtaining consent from the woman consumes time and contributes to the delay of care and potential complications.

I do not dare to risk a minute explaining procedures to her because she has nothing to lose if the procedure is done for her as long as it is medically indicated. However, if I keep explaining things, I cannot timely do what I am supposed to do, and things may get out of control and that will put me in trouble. (female midwife, urban hospital)

Participants felt that disrespect and abuse may be necessary at times to save the mother and her baby. They perceived that it is necessary to ensure the safety of the mother and her baby and avoid personal professional consequences of an adverse outcome.

\section{Disrespect and Abuse is Used as a Tool to Assert Power}

Some participants thought that disrespect and abuse arises from feelings of inferiority and professional inadequacy of care providers. Limited communication and lack of mutual decision-making between providers and women and their families was also mentioned as a reason for disrespect and abuse.

\section{Disrespect and Abuse Arises from Feelings of Inferiority and Professional Inadequacy}

Some participants preferred not to attend certain clients due to their personal attributes. They had a perception that urban and educated women are not respectful and thus they use disrespect and abuse as a tool to assert power. These providers had a feeling that educated, rich women look down on them whereas rural women are more submissive and obedient.

I prefer attending to thousand rural women than a single urban woman. Rural women are obedient whereas the urban woman challenge you on everything you do. You do not repeat instruction for rural women they comply with the first order. What do you feel when some urban women look down on you because of their economic circumstance or educational level? It drives me crazy, and I will retaliate by abandoning her or giving priority for others. (male midwife, urban hospital)

Another participant had similar views,

Some urban women try to undermine us. They think they are privileged and want us to do what we do not usually do for others. I will degrade her from humanity and teach her obedience and decency. (female midwife, urban health center)

Similarly, another participant said,

you must be blessed with patience to complete every delivery process with success. From my experience, sometimes you need to be rough for missy kind of mothers. (male midwife, from urban hospital)

Some participants believed that allowing a birth companion will interfere with their "work freedom." This may be because they are not confident that their treatment of the woman is in line with professional standards.

We do everything in our power to disallow companions. Because we do not want the companion to see how we treat the woman in the delivery room. I am not confident our practice is in line with the national guideline. However, if she is alone, you can do whatever you like in peace. She is in your hand (female midwife, urban hospital)

Providers complained that they lack training and instruments to assist women in positions other than the traditional lithotomy position. However, the only midwife who is assisting women in their preferred birthing position said,

providers consider only what is comfortable for them. Lithotomy is convenient for the provider to take the baby. Other positions compromise providers comfort as they require them to kneel or squat. Thus, providers use lack of training and material to assist woman in other positions as an excuse.

Another participant's remark supports this argument.

It is not about the woman; it is comfortable for the provider to assist and receive the baby. You can clearly see and support her perineum to prevent tear. But when you are asked about other positions you complain about lack of instruments and training. (male midwife, rural health center)

One participant totally disagreed with the importance of supporting preferred birthing positions and blamed the respectful care guideline for introducing "uncustomary" practice. 
It is not practiced, and our women do not ask for it either. Lithotomy is the only position they know. I gave birth in lithotomy position. It is the protocol that has a problem, why it requires us to do something that is not customary? I am not doing it. (female midwife, urban hospital)

\section{Disrespect and Abuse Occurs When Providers Limit Communication and Opportunities for Mutual Decision Making}

There were participants who believed that a woman has no role in her care and should passively receive care. According to these participants, women know little about the physiology of pregnancy and childbirth and there is no point in discussing it with them or explaining procedures to them as they cannot understand the "complex" care. In addition, interviewed providers indicated that laboring mothers often do not know what is best for them. For these providers, the main criterion to perform a procedure is its indication, not the woman's consent.

It is acceptable to perform a necessary procedure even if the woman did not consent to it. I do not give her a chance to ask a question or decline the procedure. Because it is me who knows what works for her. (female midwife, urban hospital)

When asked what they would need from a woman and her family to provide supportive care, some participants stressed that they prefer obedient clients and companions that do not ask questions. According to these participants, clients and companions should not be asked for consent as they know little about the procedures and the provider should be the sole decision maker in the care.

I am the professional and I am the only right person to decide on procedures. What do the woman, or her family know about the care that I ask them for a consent? (female midwife, urban hospital)

Some participants indicated they do not explain procedures to the women as they believe it is unnecessary and out of their remit. According to these participants, the primary aim of the care is to deliver the baby, not to teach the woman about the care she is receiving. As a result, explaining the care to the recipient is not seen as their job.
I am a midwife not a teacher and thus I am not supposed to explain everything to the women. (female midwife, urban hospital)

A male midwife from same facility shared similar view,

I am not here to teach women, only to attend. It is too much to ask a midwife to explain procedures to women.

Some even question the importance of obtaining consent.

Will the woman sit for exam after the procedure? Why would I waste my time and energy explaining everything to her then? (female midwife, urban health center)

Further still, some participants, not only withhold information, but also, prefer not to hear from the woman or her families at all.

Let alone explaining to her, I do not want to communicate with her or her family. I just want her to deliver and leave. (female midwife, rural health center)

For these participants disrespect and abuse arises from feelings of inferiority and professional inadequacy or when there is limited communication and mutual decisionmaking between providers and women and their families.

\section{Disrespect and Abuse Arise from Health System Deficiencies}

There were participants who thought disrespect and abuse arises from an unsupportive management and professional hierarchy. Others believed that dissonance between knowledge and practice and limited human and material infrastructure exacerbated disrespect and abuse.

\section{Disrespect and Abuse Arises from an Unsupportive Management and Professional Hierarchy}

Midwife participants were not happy with their relationship with their supervisors. They perceived that supervisors are not treating midwifery profession with the respect they feel it deserves, and this in turn is making them unkind to their clients.

The management is not fulfilling what we want to do our work. That is why I feel my profession is neglected. To be respectful, I have to be respected first. (female midwife, urban hospital) 
Additionally, mistreatment of the low and middle level providers by higher level providers was mentioned as a reason why providers are not treating women better.

Higher level providers undermine the middle and lower-level providers, the management favour higher level providers' interest. This disappoints and influences our interaction with women and contribute to their mistreatment. (female midwife, urban hospital)

Midwives felt they spend most of their time with the laboring mother and do the hard work. However, they do not feel valued.

We are doing the hard job at the frontline, but I do not feel valued as a professional and this has demotivated me (male midwife, urban hospital)

Another participant expressed a similar view,

Neither we nor the mothers are happy with the care we are providing. The way midwives are treated by the hospital administration determines how midwives treat women. (Male midwife, urban hospital)

As a result, some midwives felt forced to leave the midwifery profession because they are tired of abusing innocent labouring women.

To speak the truth, it is a novel work. In the contrary though, we are not appreciated for what we are doing in resource limited setup. That is why we beat a laboring woman. I would rather change my profession than abusing a labouring woman who has nothing to do with my problem. (female midwife, urban hospital)

What another female midwife from a rural health center said strengthens this argument.

Many midwives have joined the new innovative medical education (NEME) program to become a doctor. Because doctors enjoy better salary and working conditions compared to midwives.

Another participant had similar perspectives,

I have decided to change my profession not because I do not like it but because the administration does not value it. I cannot keep mistreating innocent women to took out my anger on the administration. (male midwife, rural health center)

\section{Disrespect and Abuse Exists When \\ Dissonance Between Knowledge and Practice Exists}

Participant midwives complained that they were not practicing what they learned in college as the facilities have restricted their job description to the delivery room. This may help explain the fatigue participants developed on birthing care.

The hospital has restricted our role only to attending delivery, nothing more. Who has the moral to judge me if I disrespect and abuse women? I am tired of it. (female midwife, urban hospital)

Another midwife from same facility said,

The hospital has anonymously decided that midwives cannot hold managerial position and have to focus on attending labouring women. We cannot be head of the ward; we cannot work in the gynaecology ward. That is why midwives became hardhearted towards labouring mothers and abuse them. (Male midwife, urban hospital)

\section{Disrespect and Abuse Occurs When Human and Material Infrastructure is Limited}

All study facilities have high client volume and a lack of staff and supplies, according to participants. The delivery ward regularly lacks supplies like medication and equipment, sufficient staff proportional to the client volume and enough space. Providers believed that they are not properly treating the women as per the guideline because of this shortage of resources.

We cannot protect women's privacy due to lack of screen or curtain, and we cannot give them sufficient time due to the workload. Thus, you cannot blame the providers for such breach of privacy and women's feeling of being ignored. (male midwife, urban hospital)

The same participant further blamed the working condition for mistreatment of women.

Providers do not intentionally disrespect or abuse a woman, but the heavy workload and stressful working environment will change their behavior and the way they interact with women.

Another participant said her workload will not let her assist women in a preferred birthing position. 
Even if I have the training and materials it takes to do so, I am not doing it because I attend more than one woman at a time, and it is not convenient. (female midwife, urban hospital)

Because of the overwhelming workload, some participants consider the regular care they provide as a favour to the women. These participants do not consider birthing care as the right of the women, rather a good will done to the mother at their mercy.

We are overcrowded, and these made you feel that you are doing favour to the mothers, not doing your job. As a result, health workers attitude towards laboring women is not good. (female midwife, urban hospital)

Providers described that the workload and shortage of resources have made them behave differently. According to these participants, providers are not happy with their working conditions and take out their anger by disrespecting and abusing women.

I am not happy with the working environment at all. It is stressful to work in a ward that is narrow, understaffed and has a shortage of medical supplies. I yell at women to takeout my anger, I am not happy. (male midwife, urban hospital)

As discussed above, while some providers felt negatively towards birth companions, others believed that birth companions are advocates and a source of strength for the laboring woman. Participants further described the importance of a companion in helping to convince the mother if she refuses a procedure, and this will make providers' job easy.

Not only will the woman but also providers benefit from presence of a birth companion. If they saw anything unacceptable being done to the mother, companions may defend. So, you will be mindful of your words and acts. This will make the relationship smooth and the work fruitful.

However, women are being denied having a companion in the study facilities due to "space constraints". A participant said,

It is the woman's right to have a birth companion. But we are not allowing them as the delivery room is too narrow. (female midwife, rural health center)

\section{Discussion}

This study explored healthcare providers' perceptions of disrespect and abuse during childbirth. Participants perceived variously that disrespect and abuse breaches professional standards, may be necessary at times to save the mother and her baby, may be used as a tool to ascertain power, and occurs due to health system deficiencies. The drivers of disrespect and abuse included stress and burnout, poor facility infrastructure including lack of medicines and supplies, and provider perceptions of women as being difficult. More than one of the above drivers were often at any given time.

However, unlike a previous study from South Africa where midwives reportedly used disrespect and abuse as a way to establish and maintain social distance between themselves and their clients, ${ }^{31}$ the primary motivator for the majority of our participants appears to be the desire to see a positive birth outcome and to avoid being blamed for a negative outcome. Midwives reported a strong sense of accountability and responsibility for positive delivery outcomes, and they explained that they would do "whatever it takes" to deliver a live baby to a healthy mother. According to these participants, disrespect and abuse tends to occur in situations where the mother is not behaving in a way that the provider perceives as beneficial to the mother or baby. They reported that in such cases, yelling, pinching, or slapping, carrying out procedures without consent, threatening the mother to comply, forcefully opening her legs, or holding her down to the delivery bed are considered acceptable Following this perception, disrespect and abuse is intertwined with a sense of professional responsibility for ensuring a physically safe birth for the laboring women in their charge. These findings are similar to a study from Ghana where midwives reported feeling a strong sense of responsibility for the delivery outcomes and as a result, yell at, and hit women to encourage them to deliver a live baby to a healthy mother. ${ }^{32}$

Adding to this complexity, some midwives described ways in which they felt urban women undermined them. This particularly occurred when female providers believed that women doubted their professional competence. Female providers have low status within the health service in Ethiopia, and arguably in society more generally. The system is not sensitive to gender equality and females are not fairly represented in tertiary education and the health work force. Some participants suggested that the best way to assert power or obtain compliance from a laboring 
woman is to yell at or abandon or even slap her. Studies from different contexts have also reported similar findings. ${ }^{28,31,33}$

Respectful care that prioritizes women's dignity and liberty, and improved communication between the woman, her family, and the providers can be promoted with proper managerial support. Midwives expect their supervisors to fairly distribute incentives and responsibilities to all professional disciplines and avail resources to provide supportive care. However, the majority of the participating midwives reported administrative bias as a source of discouragement that is preventing them from properly fulfilling their responsibilities. They perceived that administrators did not treat them as well as physicians. Professional hierarchy is rarely seen as supportive by healthcare providers but when present, good leadership changes the experience of both women and care providers. ${ }^{34}$ Absence of good leadership affects the quality of care rendered and may manifest through disrespect and abuse of laboring women. Previous research has identified that anxiety in providers is associated in particular with conflicts at work between staff and supervisors. ${ }^{35}$ This could help explain why more midwives, who reported bias, than doctors have considered the disrespect and abuse examples acceptable A study from Nigeria similarly revealed that midwives found mistreatment to be acceptable practice, compared to doctors. ${ }^{36}$ In this study, participant doctors did not report unfair treatment by facility administration and workload. This is likely related to the fact that they do not attend normal deliveries and are called to the ward only for cesarean section or to handle complications, an experience reported elsewhere in the literature. $^{37}$

Women have the right to assume any position comfortable to them while giving birth in the facility and restraining a woman from choosing a birthing position of her choice is violation of her right. ${ }^{38}$ Thus, alternative locations to the general labor and delivery floor have to be provided for those women accustomed to squatting. Unfortunately, only a single provider reported assisting mothers in their preferred birthing position. Believing they are acting to save the infant, other midwives not only deny this right but also consider it acceptable to forcefully hold down women to the delivery bed. Confinement of women to bed during labor and delivery has also been acknowledged as a common and normal practice elsewhere ${ }^{39}$ because most providers consider what is comfortable for them, not the woman. The providers participating in this study also reported that they limit birthing position to lithotomy for their own comfort and use lack of training and instrument as an excuse not to assist women in other positions.

Women have the right to be treated with respect and consideration. Thus, care providers must acknowledge that every woman is a person of value and is worthy of respect. Words and non-verbal communication of providers must honor the dignity of each woman. However, participants did not seem to appreciate the psychological trauma of non-dignified care where they threaten women with a poor outcome or unfavorable medical procedures in order to get compliance. Worse still these providers believe that threatening has no harm to the mother. A South African study also revealed that providers believe that threatening and raising their voice are sometimes the only things that work. $^{34}$

Birthing care has to be participatory. The woman and her family should actively engage in the care and be part of decision making. It is important for midwives to collaborate with women in labor by inviting them to participate and be responsible for their care during childbirth. ${ }^{40}$ However, women were not given the opportunity to clarify doubts or ask questions. Doctors and midwives did not provide important information on reasons for, or outcomes of physical examinations, progress of labor and the health of the baby, because providers believed women do not understand explanations and are unable to participate in decision-making. Thus, providers want women just to follow their instructions. In addition, they discouraged birth companions, thus not allowing for other people to advocate on behalf of the labouring woman. Studies from varying contexts have reported likewise. ${ }^{41-45}$

It is too simplistic to attribute poor quality of care, including lack of respectful care, solely to the healthcare providers. However, the social, economic and health system barriers healthcare providers experience in their daily working lives can be significant. The task of practicing midwifery in low-income countries appears to be more difficult than ever, particularly in settings where resources for maternal health care services are limited. ${ }^{46}$ Understaffing and overcrowding on the labor ward can create a stressful work environment. ${ }^{47}$ The participants of the current study have blamed mistreatment during childbirth on a disempowering health system where providers are overworked, and facilities are understaffed and overcrowded. Multinational research has indicated that disrespect and abuse is often a greater problem in developing 
countries where inadequate numbers of care providers serve a large number of clients. ${ }^{48}$ Likewise, studies from varying contexts have identified health systems constraints, staff shortages and lack of resources, as drivers for disrespect and abuse. ${ }^{34,49}$ These conditions contribute to healthcare providers' feelings of impulsivity, lower tolerance for aberration, and exhaustion, and can contribute to transference of aggression to the woman. ${ }^{33}$

\section{Limitations and Strengths of the Study}

This study was carried out in five health facilities among self-selected participants in the North Showa zone. Therefore, this may not reflect the perceptions of care providers in other parts of Ethiopia. However, participants with diverse age, education and years of experience were involved in the study which contributes to the diversity of perspectives included.

\section{Conclusion and Recommendation}

In addition to poor provider attitudes, our findings suggest that health system constraints and working under high levels of stress has influenced participants' relationship with women. Strengthening the health systems to address the system-level stressors would enhance provider-client relationship and improve quality of maternity care. Furthermore, in-service provider training that focuses on women's perspectives, rights and cultural roles in society is necessary to change attitudes. Supportive supervision and mentoring could also help to empower providers to manage difficult situations and develop positive coping mechanisms for stress. Policies and procedures that describe the responsibilities of healthcare providers in the respectful maternal care process should be developed and reinforced through education and audit processes. Respectful care should be a central pillar of entry-level nursing, midwifery and medical curricula.

\section{Abbreviations}

D\&A, Disrespect and Abuse.

\section{Data Sharing Statement}

The data that support the findings of this study are available from The University of Adelaide, but restrictions apply to the availability of these data, which were used under license for the current study, and so are not publicly available. Data are however available from the authors upon reasonable request and with permission of The University of Adelaide.

\section{Ethical Considerations}

Ethical approval was obtained from the University of Adelaide human research ethics committee H-2019-153 and Salale University College of health sciences research ethics review committee $\mathrm{A} / \mathrm{G} / \mathrm{H} / \mathrm{S} / \mathrm{C} / 768 / 11$. Salale University gave the clearance as the study was conducted in its catchment area. Letter of confirmation was received from the included health facilities that the facilities will not take disciplinary actions on care provider participants based on finding of the study. Participants were informed about research objective, what data will be collected, confidentiality of information, and voluntary nature of participation. In addition, they were informed the time the interview will take and that they reserve a right to withdraw from the study any time and there will be no direct benefit from participation. Also, no information which may identify an individual will be required for the study, and the data will not be used for future research. Data were collected only after informed written consent was obtained. The participants' informed consent included publication of anonymized responses, and that this study was conducted in accordance with the Declaration of Helsinki.

\section{Acknowledgments}

We would like to express our sincere gratitude to the care providers who participated in this study. We would also like to thank Mr. Assegid Negash for his kind support on data analysis.

\section{Author Contributions}

All authors made a significant contribution to the work reported, whether that is in the conception, study design, execution, acquisition of data, analysis and interpretation, or in all these areas; took part in drafting, revising or critically reviewing the article; gave final approval of the version to be published; have agreed on the journal to which the article has been submitted; and agree to be accountable for all aspects of the work.

\section{Funding}

This project is funded by a PhD scholarship to YMA from The University of Adelaide. 


\section{Disclosure}

The authors declare that they have no competing interests in this work.

\section{References}

1. Lozano R, Wang H, Foreman KJ, et al. Progress towards millennium development goals 4 and 5 on maternal and child mortality: an updated systematic analysis. Lancet. 2011;378(9797):1139-1165. doi:10.1016/S0140-6736(11)61337-8

2. Friberg IK, Kinney MV, Lawn JE, et al. Sub-Saharan Africa's mothers, newborns, and children: how many lives could be saved with targeted health interventions? PLoS Med. 2010;7(6):e1000295. doi:10.1371/journal.pmed.1000295

3. Campbell OM, Graham WJ. Strategies for reducing maternal mortality: getting on with what works. Lancet. 2006;368(9543):1284-1299. doi:10.1016/S0140-6736(06)69381-1

4. Shiferaw S, Spigt M, Godefrooij M, Melkamu Y, Tekie M. Why do women prefer home births in Ethiopia? BMC Pregnancy Childbirth. 2013;13(1):5. doi:10.1186/1471-2393-13-5

5. Siyoum M, Astatkie A, Mekonnen S, et al. Home birth and its determinants among antenatal care-booked women in public hospitals in Wolayta Zone, southern Ethiopia. PLoS One. 2018;13(9): e0203609. doi:10.1371/journal.pone.0203609

6. Bohren MA, Hunter EC, Munthe-Kaas HM, Souza JP, Vogel JP, Gülmezoglu AM. Facilitators and barriers to facility-based delivery in low-and middle-income countries: a qualitative evidence synthesis. Reprod Health. 2014;11(1):71. doi:10.1186/1742-4755-11-71

7. Idris SH, Sambo MN, Ibrahim MS. Barriers to utilisation of maternal health services in a semi-urban community in northern Nigeria: the clients' perspective. Nigerian Med J. 2013;54(1):27. doi:10.4103/ 0300-1652.108890

8. Garedew M, Kerie M, Walle A. Choice of healthcare providing facility and associated factors among government employees in Nekemte Town, Western Part of Ethiopia. Health Syst Policy Res. 2019;6(1):83.

9. Gebremichael MW, Worku A, Medhanyie AA, Berhane Y. Mothers' experience of disrespect and abuse during maternity care in northern Ethiopia. Glob Health Action. 2018;11(1):1465215. doi:10.1080/ 16549716.2018 .1465215

10. Molla M, Muleta M, Betemariam W, Fesseha N, Karim A. Disrespect and abuse during pregnancy, labour and childbirth: a qualitative study from four primary healthcare centres of Amhara and Southern Nations Nationalities and People's Regional States, Ethiopia. Ethiop J Health Dev. 2017;31(3):129-137.

11. Mehretie Adinew Y, Abera Assefa N. Experience of facility based childbirth in rural Ethiopia: an exploratory study of women's perspective. J Pregnancy. 2017;2017:1-6. doi:10.1155/2017/7938371

12. Mehretie Adinew Y, Abera Assefa N, Mehretie Adinew Y. Why do some Ethiopian women give birth at home after receiving antenatal care? Phenomenological study. Biomed Res Int. 2018;2018:1-8. doi:10.1155/2018/3249786

13. Ephi M. Ethiopian Demographic and Health Survey 2019. Rockville, Maryland, USA: The DHS Program ICF; 2021.

14. World Health Organization. Trends in Maternal Mortality 2000 to 2017: Estimates by WHO, UNICEF, UNFPA, World Bank Group and the United Nations Population Division. Geneva: World Health Organization; 2019.

15. World Health Organization. The Prevention and Elimination of Disrespect and Abuse During Facility-Based Childbirth: WHO Statement. World Health Organization; 2014.

16. Filippi V, Ronsmans C, Campbell OM, et al. Maternal health in poor countries: the broader context and a call for action. Lancet. 2006;368 (9546):1535-1541. doi:10.1016/S0140-6736(06)69384-7
17. d'Oliveira AFPL, Diniz SG, Schraiber LB. Violence against women in health-care institutions: an emerging problem. Lancet. 2002;359 (9318):1681-1685. doi:10.1016/S0140-6736(02)08592-6

18. Davis-Floyd R. Global issues in midwifery: mutual accommodation or biomedical hegemony. Midwifery Today Int Midwife. 2000;53:12-16.

19. Koblinsky M, Moyer CA, Calvert C, et al. Quality maternity care for every woman, everywhere: a call to action. Lancet. 2016;388 (10057):2307-2320. doi:10.1016/S0140-6736(16)31333-2

20. Barry CA, Stevenson FA, Britten N, Barber N, Bradley CP. Giving voice to the lifeworld. More humane, more effective medical care? A qualitative study of doctor-patient communication in general practice. Soc Sci Med. 2001;53(4):487-505. doi:10.1016/S0277-9536(00)00351-8

21. Lambert J, Etsane E, Bergh A-M, Pattinson R, Van den Broek N. I thought they were going to handle me like a queen but they didn't': a qualitative study exploring the quality of care provided to women at the time of birth. Midwifery. 2018;62:256-263. doi:10.1016/j. midw.2018.04.007

22. Burrowes S, Holcombe SJ, Jara D, Carter D, Smith K. Midwives' and patients' perspectives on disrespect and abuse during labor and delivery care in Ethiopia: a qualitative study. BMC Pregnancy Childbirth. 2017;17(1):263. doi:10.1186/s12884-017-1442-1

23. Adinew YM, Hall H, Marshall A, Kelly J. Disrespect and abuse during facility-based childbirth in central Ethiopia. Glob Health Action. 2021;14(1):1923327. doi:10.1080/16549716.2021.1923327

24. Caelli K, Ray L, Mill J. 'Clear as mud': toward greater clarity in generic qualitative research. Int J Qual Methods. 2003;2(2):1-13. doi:10.1177/160940690300200201

25. Neergaard MA, Olesen F, Andersen RS, Sondergaard J. Qualitative description-the poor cousin of health research? BMC Med Res Methodol. 2009;9(1):1-5. doi:10.1186/1471-2288-9-52

26. CSA. Summary and Statistical Report of 2007 Population and Housing Censes. Federal Democratic Republic of Ethiopia Census Commission. Addis Abeba: Central Statistics Authority; 2007.

27. Bohren MA, Vogel JP, Hunter EC, et al. The mistreatment of women during childbirth in health facilities globally: a mixed-methods systematic review. PLoS Med. 2015;12(6):e1001847. doi:10.1371/journal.pmed.1001847

28. Asefa A, Bekele D. Status of respectful and non-abusive care during facility-based childbirth in a hospital and health centers in Addis Ababa, Ethiopia. Reprod Health. 2015;12(1):33. doi:10.1186/ s12978-015-0024-9

29. Braun V, Clarke V. Using thematic analysis in psychology. Qual Res Psychol. 2006;3(2):77-101. doi:10.1191/1478088706qp063oa

30. Tong A, Sainsbury P, Craig J. Consolidated criteria for reporting qualitative research (COREQ): a 32-item checklist for interviews and focus groups. Int J Qual Health Care. 2007;19(6):349-357. doi:10.1093/intqhe/mzm042

31. Jewkes R, Abrahams N, Mvo Z. Why do nurses abuse patients? Reflections from South African obstetric services. Soc Sci Med. 1998;47(11):1781-1795. doi:10.1016/S0277-9536(98)00240-8

32. Yakubu J, Benyas D, Emil SV, Amekah E, Adanu R, Moyer CA. It's for the greater good: perspectives on maltreatment during labor and delivery in rural Ghana. Open J Obstet Gynecol. 2014;2014:8. doi:10.4236/ojog.2014.47057

33. Bobo FT, Kasaye HK, Belachew Etana MW, Feyissa TR. Disrespect and abuse during childbirth in Western Ethiopia: should women continue to tolerate? PLoS One. 2019;14(6). doi:10.1371/journal. pone. 0225996

34. Schoombee JC, van der Merwe JM, Kruger LM. The stress of caring: the manifestation of stress in the nurse-patient relationship. Soc Work/ Maatskaplike Werk. 2005;41(4). doi:10.15270/41-4-318

35. Bennett P, Lowe R, Matthews V, Dourali M, Tattersall A. Stress in nurses: coping, managerial support and work demand. Stress Health. 2001;17(1):55-63. doi:10.1002/1532-2998(200101)17:1<55::AID$\mathrm{SMI} 879>3.0 . \mathrm{CO} ; 2-2$ 
36. Bohren MA, Vogel JP, Tunçalp Ö, et al. Mistreatment of women during childbirth in Abuja, Nigeria: a qualitative study on perceptions and experiences of women and healthcare providers. Reprod Health. 2017;14(1):9. doi:10.1186/s12978-016-0265-2

37. Fujita N, Perrin XR, Vodounon JA, et al. Humanised care and a change in practice in a hospital in Benin. Midwifery. 2012;28 (4):481-488. doi:10.1016/j.midw.2011.07.003

38. Lawrence A, Lewis L, Hofmeyr GJ, Styles C. Maternal positions and mobility during first stage labour. Cochrane Database Syst Rev. 2013; (8). doi:10.1002/14651858.CD003934.pub3

39. Jeng B. Practices and Quality of Intrapartum Care in the Main Referral Hospital of the Gambia; 2008.

40. Lundgren I, Dahlberg K. Midwives' experience of the encounter with women and their pain during childbirth. Midwifery. 2002;18 (2):155-164. doi:10.1054/midw.2002.0302

41. Weeks A, Lavender T, Nazziwa E, Mirembe F. Personal accounts of 'near-miss' maternal mortalities in Kampala, Uganda. BJOG. 2005;112(9):1302-1307. doi:10.1111/j.1471-0528.2005.00703.x

42. Afsana K, Rashid SF. The challenges of meeting rural Bangladeshi women's needs in delivery care. Reprod Health Matters. 2001;9 (18):79-89. doi:10.1016/S0968-8080(01)90094-1

43. Kabakian-Khasholian $T$, Campbell O, Shediac-Rizkallah M, Ghorayeb F. Women's experiences of maternity care: satisfaction or passivity? Soc Sci Med. 2000;51(1):103-113. doi:10.1016/S02779536(99)00443-8
44. Murira N, Lützen K, Lindmark G, Christensson K. Communication patterns between health care providers and their clients at an antenatal clinic in Zimbabwe. Health Care Women Int. 2003;24(2):83-92. doi:10.1080/07399330390170060

45. Maputle SM, Hiss D. Midwives' experiences of managing women in labour in the Limpopo Province of South Africa. Curationis. 2010;33 (3):5-14. doi:10.4102/curationis.v33i3.2

46. Colvin CJ, de Heer J, Winterton L, et al. A systematic review of qualitative evidence on barriers and facilitators to the implementation of task-shifting in midwifery services. Midwifery. 2013;29 (10):1211-1221. doi:10.1016/j.midw.2013.05.001

47. Rouleau D, Fournier P, Philibert A, Mbengue B, Dumont A. The effects of midwives' job satisfaction on burnout, intention to quit and turnover: a longitudinal study in Senegal. Hum Resour Health. 2012;10(1):1-14. doi:10.1186/1478-4491-10-9

48. Bohren MA, Mehrtash H, Fawole B, et al. How women are treated during facility-based childbirth in four countries: a cross-sectional study with labour observations and community-based surveys. Lancet. 2019;394(10210):1750-1763. doi:10.1016/S0140-6736(19) 31992-0

49. Warren CE, Njue R, Ndwiga C, Abuya T. Manifestations and drivers of mistreatment of women during childbirth in Kenya: implications for measurement and developing interventions. BMC Pregnancy Childbirth. 2017;17(1):1-14. doi:10.1186/s12884-017-1288-6
International Journal of Women's Health

\section{Publish your work in this journal}

The International Journal of Women's Health is an international, peerreviewed open-access journal publishing original research, reports, editorials, reviews and commentaries on all aspects of women's healthcare including gynecology, obstetrics, and breast cancer. The manuscript management system is completely online and includes a very quick and fair peer-review system, which is all easy to use. Visit http://www.dovepress.com/testimonials.php to read real quotes from published authors. 